\title{
The synergistic anticancer effect of cisplatin combined with Oldenlandia diffusa in osteosarcoma MG-63 cell line in vitro
}

This article was published in the following Dove Press journal:

OncoTargets and Therapy

II January 2016

Number of times this article has been viewed

\section{Feifei $\mathrm{Pu}$ \\ Fengxia Chen ${ }^{2}$ \\ Song Lin' \\ Songfeng Chen' \\ Zhicai Zhang' \\ Baichuan Wang' \\ Zengwu Shao'}

'Department of Orthopedics, Union Hospital, Tongji Medical College,

Huazhong University of Science and Technology, ${ }^{2}$ Department of Medical Oncology, General Hospital of The Yangtze River Shipping, Wuhan, Hubei, People's Republic of China
Correspondence: Zengwu Shao Department of Orthopedics, Union Hospital, Tongji Medical College, Huazhong University of Science and Technology, 1277 Jiefang Avenue, Wuhan, Hubei 430022, People's Republic of China Emailszwjj@medmail.com.cn
Background: Oldenlandia diffusa (OD) is a well-known traditional Chinese medicine, which is used to prevent and treat many disorders, especially cancers. However, its role in osteosarcoma has not been well understood. Here, we used OD and cisplatin individually and combined in osteosarcoma MG-63 cell to explore whether OD could induce cellular apoptosis and suppress the ability of proliferation and invasion of osteosarcoma MG-63 cell.

Methods: The changes of cellular shape were analyzed by optical microscopy. 3-(4,5-Dimethylthiazol-2-yl)-2,5-diphenyltetrazoliumbromide assay was used to analyze cell survival rate in vitro. Flow cytometry was performed to detect cell cycle and cell death. Scratch migration assay was used to evaluate cell migration and invasion. Western blot was performed to determine the expression levels of pro-apoptotic and anti-apoptotic protein.

Results: In this study, we found that the survival rate reduced significantly in the combined group compared with the individual group and control group. The apoptosis-inducing effect of combined application was much more significant than that of individual application. The invasion ability of combined application was significantly lower than that of the individual application. In the combined group, there were high expression levels of pro-apoptotic protein and low expression of anti-apoptotic protein. Cell-cycle analysis showed a change in the cellcycle distribution and arrested cells in G2-M phase.

Conclusion: In this study, we found that OD inhibited proliferation and induced apoptosis in the human osteosarcoma MG-63 cell line in a time-dependent and dose-dependent manner. In addition, OD displayed inhibitory activity on MG-63 cell proliferation and invasion and the study also showed that OD activity might be mediated by caspase activation. These data suggest that OD might represent a novel, efficient candidate agent for further experimentation in osteosarcoma treatment.

Keywords: Oldenlandia diffusa, cisplatin, osteosarcoma, apoptosis, in vitro

\section{Introduction}

Osteosarcoma derives from primitive bone-forming mesenchymal cells, and it is the most common malignant tumor of bones and is one of the leading causes of death from cancer in children and adolescents. ${ }^{1}$ Standard treatment of osteosarcoma involves neoadjuvant therapy before definitive resection of the primary tumor, and followed by multiple chemotherapeutic agents after operation. ${ }^{2}$ Nevertheless, more than $40 \%$ of patients have a poor tumor response to chemotherapy, and the estimated survival is about $45 \%-55 \%$, the 5 -year overall relapse-free survival rate is about $65 \%$. 3,4

Early in the 1960s and 1970s, cis-diamminedichloroplatinum(II) (cisplatin) was discovered to eliminate and regress the tumor. ${ }^{5}$ The neoadjuvant chemotherapy including cisplatin has been confirmed to treat possible microscopic metastases, eliminate or regress 
tumor, and thereby increase the possibility of limb-sparing surgery. ${ }^{6}$ Interestingly, the sensitivities to neoadjuvant chemotherapy were different in osteosarcoma patients. Cisplatin is currently a common chemotherapeutic drug in the treatment of osteosarcoma and it is one of the first-line anticancer drugs for regular chemotherapy in clinical treatment. It remains the key drug to overcome inherent tumor resistance for osteosarcoma therapy, but occurrence of drug resistance and considerable side effects make it imperative to develop less toxic and more effective approaches to overcome these limitations. ${ }^{7}$

Chinese herbal remedies are used by traditional Chinese medicine practitioners to treat various kinds of cancer and are recognized as a potential source of novel therapeutic agents. Zhou et $\mathrm{al}^{8}$ found that kurarinone can synergize tumor necrosis factor-related apoptosis-inducing ligand-induced apoptosis in gastric cancer cells. Oldenlandia diffusa (OD) is a member of the Rubiaceae family of Chinese herbal remedies, and the Latin botanical name is Hedyotis diffusa. It is mainly found in the southeastern provinces of the People's Republic of China and grows at low altitudes, mainly in moist fields. A study showed that OD extracts exerted antiproliferative and apoptotic effects on human breast cancer cells through ER $\alpha /$ Sp1-mediated p53 activation. ${ }^{9}$ The water extracts of OD have been shown to have apoptotic effect in the leukemic cell line HL60 and human primary blood lymphocytes. ${ }^{10}$

Because of the fact that a number of anticancer phytochemicals from herbal medicines are attractive due to limited side effects, and their ability to sensitize cancer cells to chemotherapy, we were interested in exploring the biological effects of OD extracts both alone and in combination with cisplatin.

\section{Materials and methods}

\section{Ethics statement}

The study was approved by the Ethics Committee of Union Hospital Tongji Medical College of Huazhong University of Science and Technology and conforms with the provisions of the Declaration of Helsinki.

\section{Preparation of OD extract}

O. diffusa was obtained from Hubei University of traditional Chinese Medicine (Hubei, People's Republic of China). According to the traditional method to produce aqueous extract of the dried herb, $10 \mathrm{~g}$ dried herb was selected and ground to powder, then extracted with $10 \mathrm{~mL}$ distilled water. The mixture was boiled for 1 hour under reflux. The mixture was then centrifuged for 30 minutes at room temperature with $3,000 \times g$ and the resultant solution was passed through a $0.45 \mu \mathrm{m}$ sterile filter. Finally, high pressure steam sterilization was carried out and then preserved at $-20^{\circ} \mathrm{C}$.

\section{Reagents}

Dimethyl sulfoxide, 3-(4,5-dimethylthiazol-2-yl)-2,5diphenyltetrazoliumbromide (MTT) was purchased from Gibco (Gaithersburg, MD, USA). Cisplatin was purchased from Qilu Pharmaceutical Co., Ltd (Jinan, Shandong, People's Republic of China). Rabbit monoclonal antibodies of caspase-3, rabbit polyclonal caspase-8, Bax, Bad, Bcl-xl, and Bcl-2 were purchased from Abcam (Cambridge, UK).

\section{Cell culture}

The osteosarcoma MG-63 was provided by Cell Bank of the Chinese Academy of Sciences (Shanghai, People's Republic of China). The cell line was cultured in RPMI 1640 medium (Boshide, Wuhan, People's Republic of China) containing $10 \%$ fetal bovine serum (FBS; Gibco, Paisley, UK) and incubated at $37^{\circ} \mathrm{C}$ in an atmosphere containing $5 \% \mathrm{CO}_{2}$.

\section{Cell proliferation assay}

The cell viability and survival rates of osteosarcoma MG-63 cells were measured using MTT method. The starting cell concentration was $5 \times 10^{5} / \mathrm{mL}$ of osteosarcoma MG-63 cells, which were seeded in the 96 -well plates with $150 \mu \mathrm{L}$ in each well, $100 \mu \mathrm{L}$ of which was added to the indicated concentrations of OD and/or cisplatin for the indicated time, each concentration in four parallel wells after adherence. After culturing for 24 hours, $20 \mu \mathrm{L}$ of MTT solution $(5 \mathrm{mg} / \mathrm{mL})$ was added to each well, and incubation continued at $37^{\circ} \mathrm{C}$ for 4 hours. After the removal of the medium, the supernatant was discarded and dissolved in $200 \mu \mathrm{L}$ DMSO. After mixing, the optical density was measured with a microplate reader (Model 550, Bio-Rad Laboratories Inc., Hercules, CA, USA) at $570 \mathrm{~nm}$ wavelength. Survival rate of MG-63 cell $(\%)=($ experimental group A value/control group A value) $\times 100 \%$. All of the results were obtained from three independent experiments.

\section{Cell-cycle analysis}

We seeded osteosarcoma MG-63 cells into 12-well plates, and cell-cycle distribution was evaluated with DNA content by using propidium iodide (PI) staining. Cells were washed with phosphate-buffered saline (PBS) twice, and then trypsinized and centrifuged at $1,500 \times g$ at $4{ }^{\circ} \mathrm{C}$ for 5 minutes. MG-63 cells treated with OD were fixed in $75 \%$ ethanol at $-20^{\circ} \mathrm{C}$ overnight. After fixation, the cells were centrifuged again and then washed with PBS twice, and incubated in PBS containing RNase A ( $1 \mathrm{mg} / \mathrm{mL})$ for 10 minutes at room temperature. Finally, the samples were stained with PI $(50 \mu \mathrm{g} / \mathrm{mL})$ for 30 minutes at room temperature. Data acquisition and the DNA contents of the stained cells were 
analyzed using flow cytometry and analyzed by CellQuest Software. All experiments were repeated three times.

\section{Apoptosis assay}

We used flow cytometry to determine apoptosis. Osteosarcoma MG-63 cells were cultured in 6-well plates overnight. Following distinct treatments, cells were harvested and washed with prechilled $4^{\circ} \mathrm{C}$ PBS twice, and centrifuged at $1,500 \times g$ for 5 minutes. After that, we discarded the supernatant and the pellet was resuspended gently in Annexin V-fluorescein isothiocyanate binding buffer and incubated with Annexin V-fluorescein isothiocyanate for 10 minutes in the dark at room temperature. Cells were centrifuged at $1,500 \times \mathrm{g}$ for 5 minutes, and the pellet was resuspended in binding buffer with PI in the dark at room temperature. Finally, the suspension of each group was analyzed by flow cytometry after filtration (300 apertures).

\section{Invasion ability assay}

We used serum-free medium to wash the chamber twice, and then added $20 \mu \mathrm{L}$ matrigel to evenly cover the surface of the polycarbonate membrane. Then, the chamber was sealed with matrigel membrane and divided into upper and lower compartments after incubating at $37^{\circ} \mathrm{C}$ for 30 minutes. An aliquot of $200 \mu \mathrm{L}$ preprocessed Dulbecco's Modified Eagle's Medium (PBS blank control group, $140 \mu \mathrm{L} / \mathrm{mL}$ OD group, $6 \mu \mathrm{g} / \mathrm{mL}$ cisplatin group, and $140 \mu \mathrm{L} / \mathrm{mL}$ OD with $6 \mu \mathrm{g} / \mathrm{mL}$ cisplatin as the combined group) with $10 \%$ FBS containing $1 \times 10^{5}$ cells was seeded in the upper chamber of the Transwell invasion system, and $500 \mu \mathrm{L}$ Dulbecco's Modified Eagle's Medium with 10\% FBS was added to the lower chamber. The Transwell invasion system was placed into cell culture incubator for 24 hours. From the upper chamber, cells on the upper surface of the membrane were removed. Finally, cells which invaded to the lower surface of the membrane were stained with $0.1 \%$ crystal violet for 15 minutes. Five fields were selected randomly by microscopy. We calculated the number of cells and photomicrographs were taken. Median number of cells was recorded. All experiments were repeated three times.

\section{Western blot analysis}

The MG-63 cells were washed with ice-cold PBS twice, and then solubilized in $1 \%$ Triton lysis buffer on ice, and quantified by the Lowry method. Cell lysate proteins were separated and transferred to nitrocellulose membrane. The membranes were blocked with 5\% nonfat milk in TBST (Tris Buffered Saline, with Tween-20) buffer for 2 hours at room temperature, and then incubated overnight at $4{ }^{\circ} \mathrm{C}$ with rabbit monoclonal antibody of caspase-3, rabbit polyclonal caspase-8, Bax, Bad,
Bcl-xl, and Bcl-2. After washing the membranes with TBST buffer three times, membranes were reacted with the appropriate horseradish peroxidase conjugated secondary antibodies for 2 hours at room temperature. After washing with TBST buffer extensively, the protein signals were visualized with enhanced chemiluminescence reagent. All the results were obtained from three independent experiments.

\section{Statistical analysis}

The experimental data were expressed as mean \pm standard deviation, and were analyzed by using SPSS 17.0 software (SPSS Inc., Chicago, IL, USA). Statistical analysis was carried out using standard analysis of variance methodology or a Student's $t$-test to assess the statistical significance between control and experimental groups of three independent experiments. A 5\% $(P<0.05)$ level of significance was considered as statistically significant.

\section{Results}

\section{Changes of survival rates of osteosarcoma MG-63 cells}

The survival rates study showed that OD exerted a toxic effect on osteosarcoma MG-63 cells at all time points, and showed concentration-dependent and time-dependent characteristics (Figure 1A and B). The $\mathrm{IC}_{50}$ using OD alone was $203.0 \mu \mathrm{L} / \mathrm{mL}$, using cisplatin alone was $8.9 \mu \mathrm{g} / \mathrm{mL}$, and using OD and cisplatin in combination was $164.6 \mu \mathrm{L} / \mathrm{mL}$ for OD and $5.0 \mu \mathrm{g} / \mathrm{mL}$ for cisplatin. The results showed that the combined use of OD and cisplatin had stronger inhibitory effect than the single agents $(P<0.01)$, and that the inhibitory effect of cisplatin was stronger than $\mathrm{OD}(P<0.05)$.

\section{Cell-cycle analysis of osteosarcoma MG-63 cells}

MG-63 cells were incubated with 0 and $140 \mu \mathrm{L} / \mathrm{mL}$ of OD for 48 hours and cell-cycle distribution was determined by flow cytometry. The results showed that OD effectively arrested the cell cycle at the $\mathrm{G} 2$ phase $(P<0.01)$ (Figure $2 \mathrm{~A}-\mathrm{C}$ ).

\section{Apoptosis changes of osteosarcoma MG-63 cells}

The results of Annexin V and PI staining showed the apoptotic rate in the combination of OD $(140 \mu \mathrm{L} / \mathrm{mL})$ and cisplatin $(6 \mu \mathrm{g} / \mathrm{mL})$ group was significantly higher than that in the control group and the individual group $(P<0.01)$, and the apoptotic rate of each individual group was higher than the control group $(P<0.01)$. However, the apoptotic rate between individual group of OD and cisplatin did not differ significantly (Figure $3 \mathrm{~A}$ and $\mathrm{B}$ ). The results indicated that $\mathrm{OD}$ 

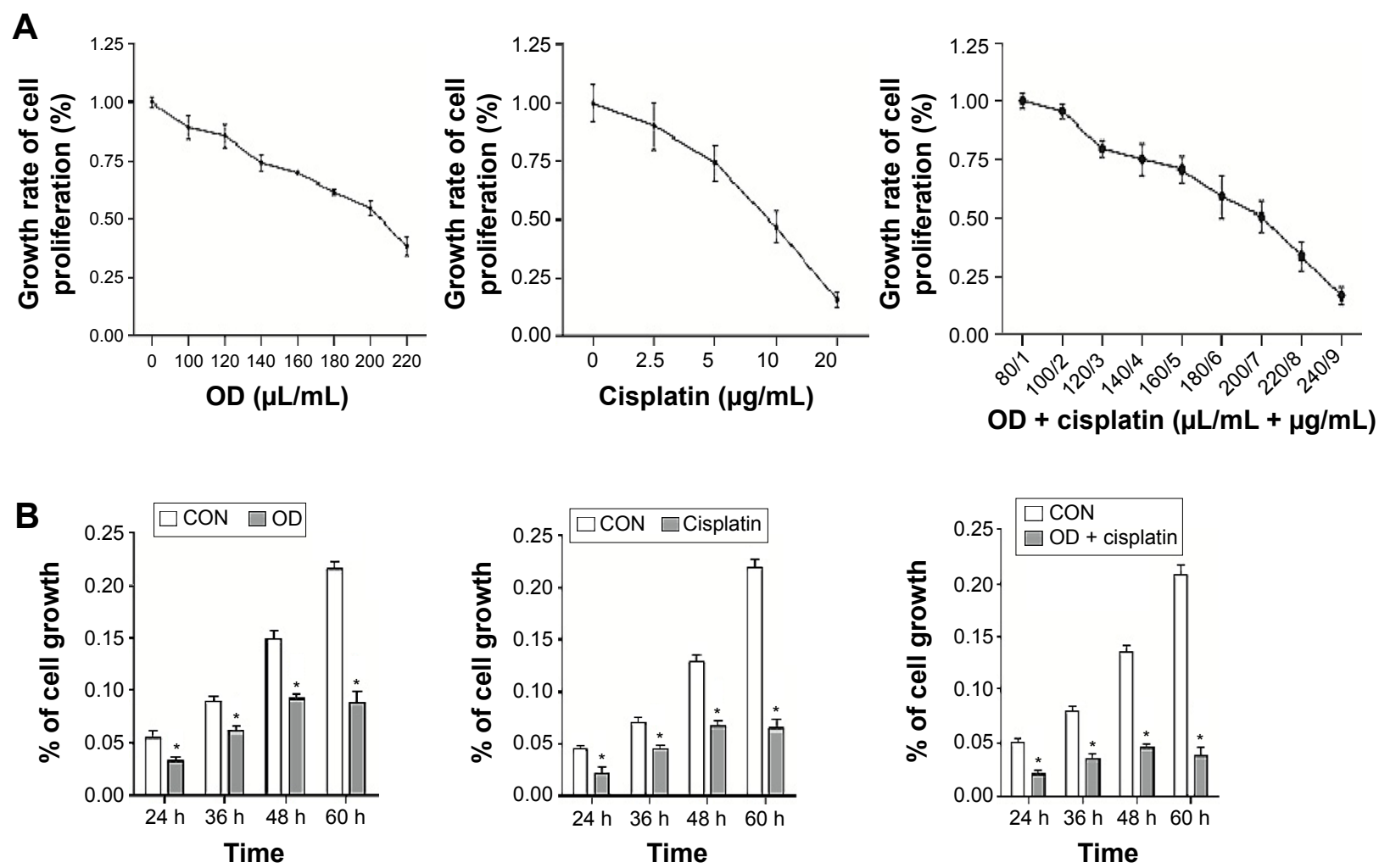

Figure I The inhibition effect on MG-63 cells measured by MTT assay.

Notes: (A) The survival rate of MG-63 cells with different concentration of OD, cisplatin, and combination of OD and cisplatin. The IC ${ }_{50}$ using OD alone was $203.0 \mu \mathrm{L} / \mathrm{mL}$, using cisplatin alone was $8.9 \mu \mathrm{g} / \mathrm{mL}$, and using OD and cisplatin in combination was $164.6 \mu \mathrm{L} / \mathrm{mL}$ for OD and $5.0 \mu \mathrm{g} / \mathrm{mL}$ for cisplatin. (B) The survival rate of MG-63 cells with different concentration of OD, cisplatin, and combination of OD and cisplatin. The cell proliferation was inhibited in a time-dependent manner and the results were obtained from three independent experiments ( $* P<0.05$ vs the control group).

Abbreviations: CON, control; MTT, 3-(4,5-dimethylthiazol-2-yl)-2,5-diphenyltetrazoliumbromide; OD, Oldenlandia diffusa.

and cisplatin in combination had a greater apoptotic effect on osteosarcoma MG-63 cells.

\section{OD inhibited cell migration and invasion of osteosarcoma MG-63 cells}

The cell scratch migration assay and invasion assay were used to corroborate the OD effects. The results showed that there were significantly fewer migrating cells in combination of OD $(140 \mu \mathrm{L} / \mathrm{mL})$ and cisplatin $(6 \mu \mathrm{g} / \mathrm{mL})$ group than the control group and the individual group $(P<0.01)$ (Figure 4), and the number of migrating cells in the cisplatin group were significantly less than that in OD group $(P<0.05)$ (Figure 4A and $B$ ). These results emphasized the inhibitive effect of OD on migration and invasion in MG-63 cells.

\section{OD altered anti-apoptotic and pro- apoptotic protein expression in osteosarcoma MG-63 cells}

We tested the expressions of Bax, Bad, Bcl-xl, Bcl-2, caspase-3, and caspase- 8 in MG-63 cells after the cells were exposed to OD $(140 \mu \mathrm{L} / \mathrm{mL})$, cisplatin $(6 \mu \mathrm{g} / \mathrm{mL})$, and a combination of OD $(140 \mu \mathrm{L} / \mathrm{mL})$ and cisplatin $(6 \mu \mathrm{g} / \mathrm{mL})$ for 48 hours. The results showed that the levels of pro-apoptotic protein (Bax and Bad) in both OD group $(140 \mu \mathrm{L} / \mathrm{mL})$ and cisplatin group $(6 \mu \mathrm{g} / \mathrm{mL})$ were higher than the control group and individual group, but the levels of anti-apoptotic protein (Bcl-xl and Bcl-2) in combination group were lower than the control group and individual group $(P<0.01)$ (Figure 5A and $\mathrm{B})$. The results showed that the levels of active caspase-3, poly (ADP-ribose) polymerase, and active caspase- 8 in both OD group $(140 \mu \mathrm{L} / \mathrm{mL})$ and cisplatin group $(6 \mu \mathrm{g} / \mathrm{mL})$ were elevated, and the levels of active caspase-3, poly (ADP-ribose) polymerase, and active caspase- 8 in the combination group was higher than the control group and individual group $(P<0.01)$ (Figure 6A-D).

\section{Discussion}

OD is a Chinese medicine, which has been extensively investigated in vitro. Recent studies on breast cancer, blood lymphocytes, small-cell lung carcinoma, and ovarian cancer showed that OD has a role in inducing apoptosis of the 


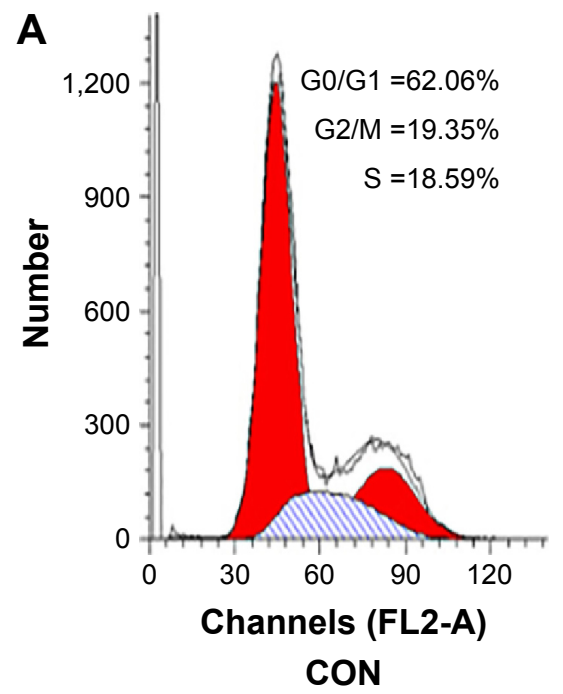

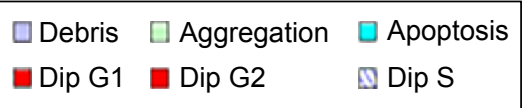
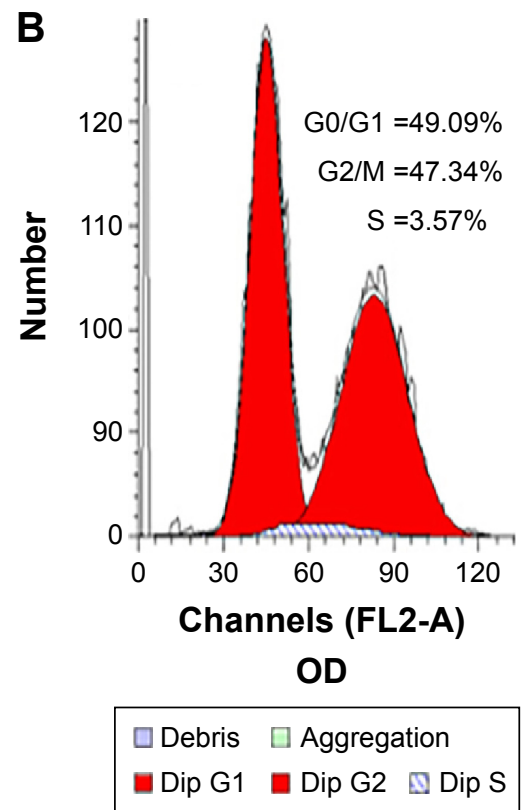

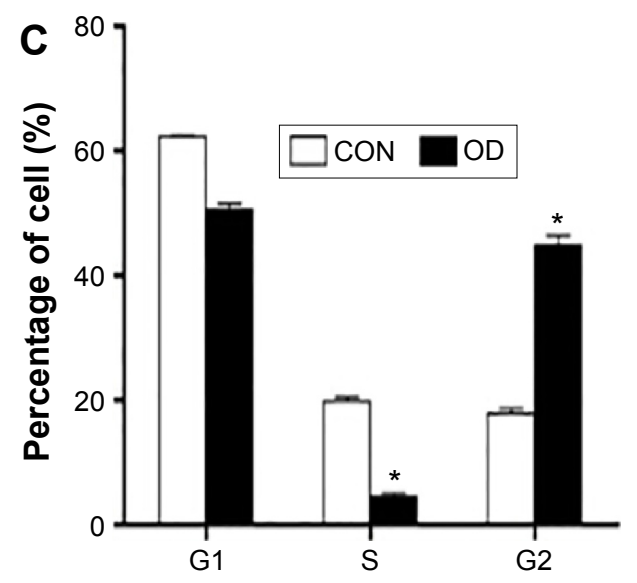

Figure 2 The cell-cycle distribution of MG-63 cells was determined by flow cytometry.

Notes: (A) Cell cycle of control group. (B) OD effectively arrested the cell cycle at the G2 phase. (C) Percentage of cell in OD and control groups. Results were obtained from three independent experiments $(* P<0.01$ vs the control group).

Abbreviations: CON, control; OD, Oldenlandia diffusa.

cancer cells, and may be an effective chemical treatment with reduced toxicity and side effects in vivo. ${ }^{9-11}$ The study has proven to be effective in inhibiting the growth of different cancer cell lines and inducing selective apoptosis in the leukemic cell line HL60, but not in human lymphocytes. ${ }^{10}$ OD has immunomodulating activity and antitumor activity in vitro through stimulating the immune system to kill or engulf tumor cells, which could be used clinically for immune function modulation and to treat tumor. ${ }^{12}$ However, its effect on osteosarcoma cells is unknown.

Cisplatin is a common cancer chemotherapy drug. A previous study had reported the combination of crocin, and the result indicated that the combination of both cisplatin and crocin had a synergistic role in inducing apoptosis and reduced the amount of cisplatin as well as its toxic side effects. ${ }^{13}$ So we have taken the experiment to apply OD on osteosarcoma MG-63 cells. In this study, the results indicated that OD inhibited the proliferation of MG-63 in a dose-dependent manner, but the cells were less sensitive to OD than to cisplatin, and the cells in combination were more sensitive than individually. We also found that the antitumor effect of cisplatin was stronger than OD.

Caspase- 8 is a protein of 480 amino acids with a $55 \mathrm{kDa}$ cysteine protease, which contains a catalytic protease domain and two death effector domains. Activation of caspase- 8 leads to caspase cascade activation where downstream effector caspase- 3 becomes activated and cleaves 

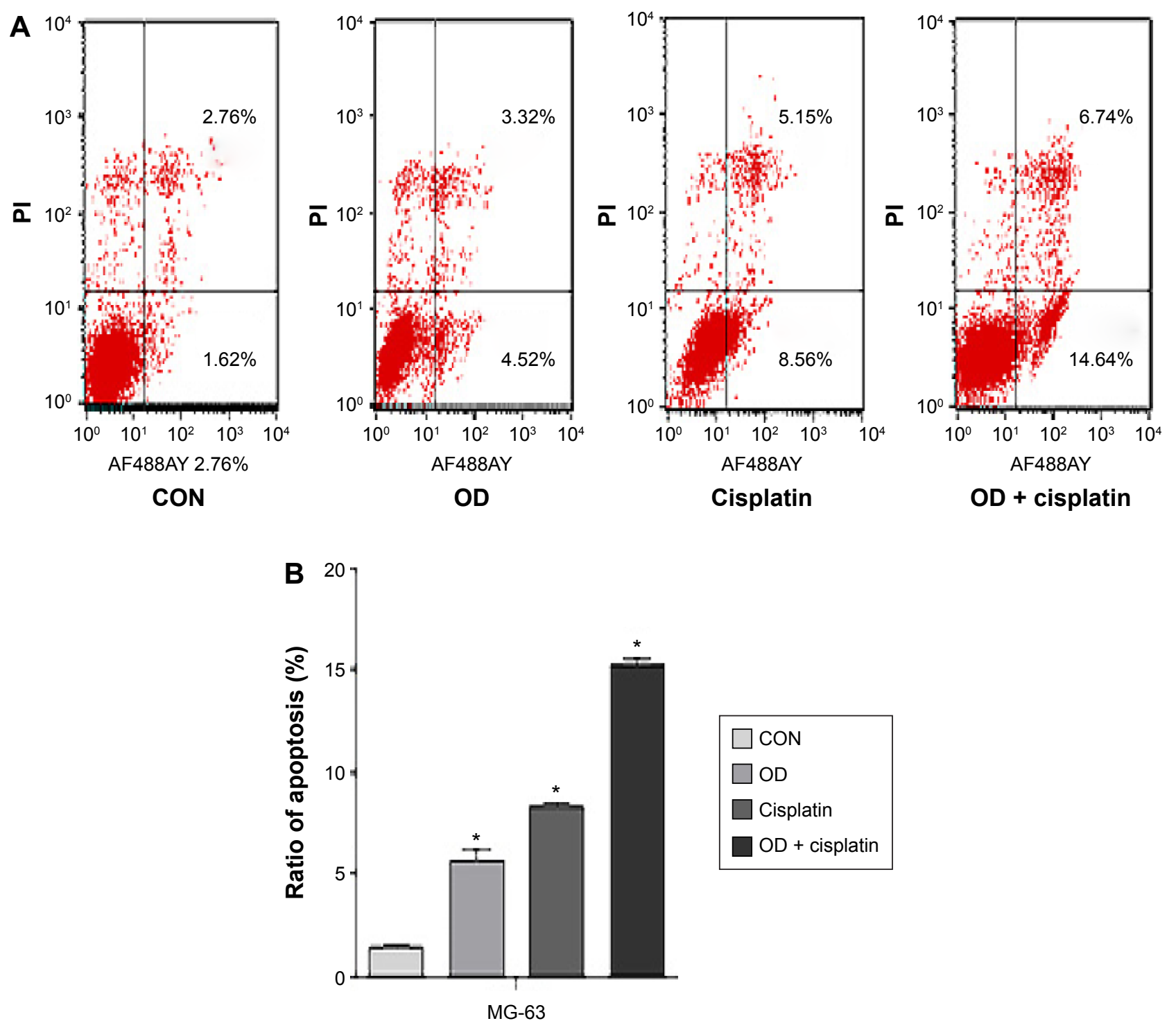

Figure 3 Apoptosis in MG-63 cells $\left(1 \times 10^{6}\right)$ treated with different concentration of OD, cisplatin, and combination of OD and cisplatin.

Notes: OD group and cisplatin group is $140 \mu \mathrm{L} / \mathrm{mL}$ and $6 \mu \mathrm{g} / \mathrm{mL}$, respectively and OD is $140 \mu \mathrm{L} / \mathrm{mL}$, cisplatin is $6 \mu \mathrm{g} / \mathrm{mL}$ in combined group. (A) Apoptosis distribution in CON, OD, cisplatin, and OD + cisplatin groups. (B) Ratio of apoptosis in CON, OD, cisplatin, and OD + cisplatin groups. The mean \pm standard deviation of the results were obtained from three independent experiments $\left({ }^{*} P<0.0 \mathrm{I}\right.$ vs the control group).

Abbreviations: CON, control; OD, Oldenlandia diffusa.

target proteins, eventually leading to cell death. ${ }^{12,13}$ In classic models, caspase-8 is depleted or inhibited frequently, which led to inhibition of apoptosis and conversion to death through a necrotic pathway. ${ }^{14,15}$ Caspase-3 is a member of the caspase family of enzymes, which are the major inducers of apoptosis. The activity of caspase- 3 is often used to measure the apoptosis in studies of antitumor drugs. A number of studies have shown that Chinese medicines can upregulate the expression of caspase-3 in tumor cells via both extrinsic and intrinsic pathways, enhancing apoptosis and promoting tumor cell death. ${ }^{16-18}$ The results of these studies suggest that both cisplatin and OD could activate caspase- 8 and upregulate the cleaved caspase-3, these may induce apoptosis by caspase pathway. Moreover, the results in this study have also shown that individual application of OD could also inhibit the osteosarcoma MG-63 cells and diminish the ability of invasion, which might be related to the caspase pathway.

These results were consistent with the view that OD might represent an adjuvant second-line anticancer agent, which might improve immunity function, while cisplatin remains a first-line anticancer drug for chemotherapy in clinical treatment. Consequently, we hypothesize that OD is suitable for further study in the treatment of osteosarcoma. 


\section{A}
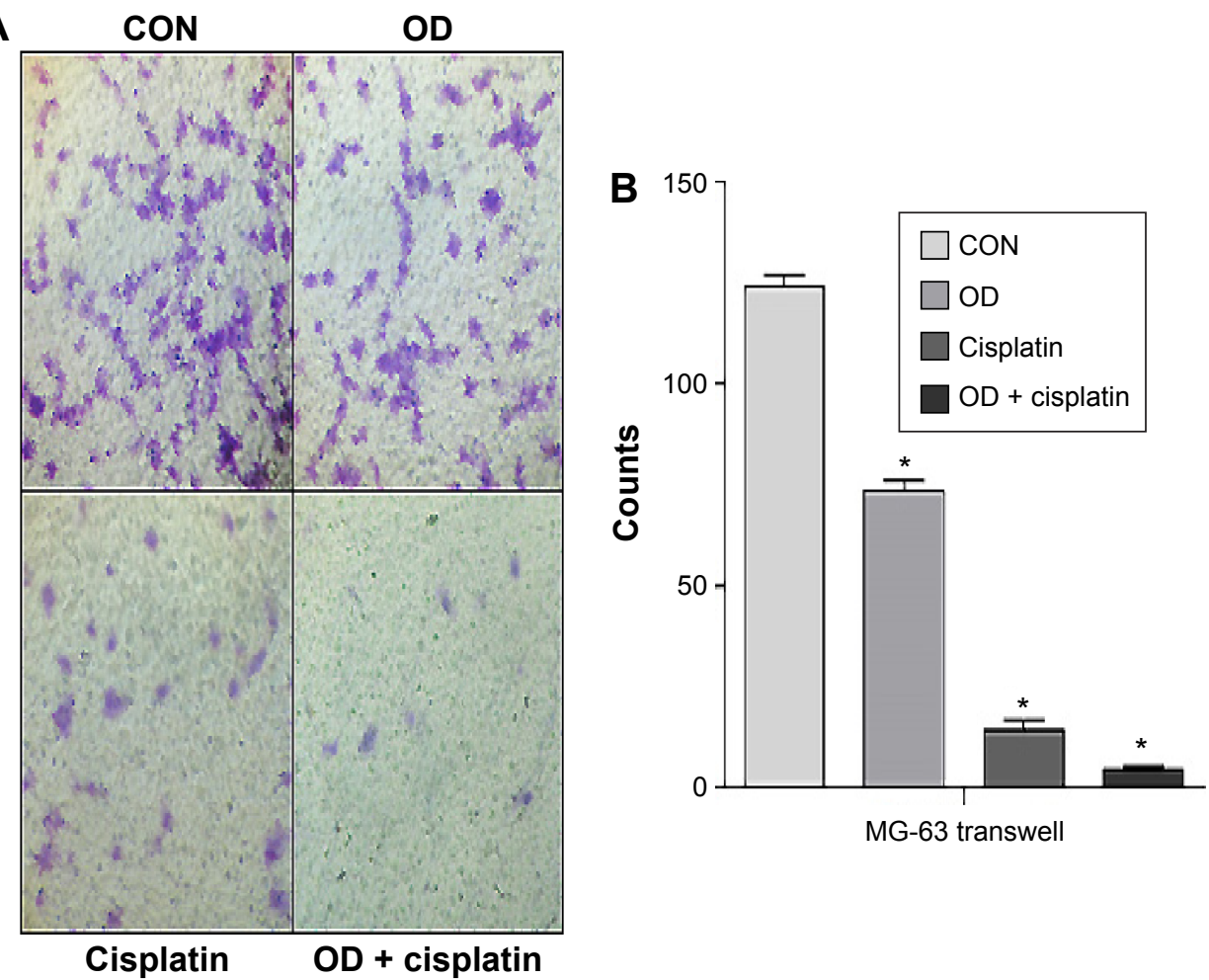

Figure 4 Invasion in MG-63 cells treated with different concentration of OD, cisplatin, and combination of OD and cisplatin.

Notes: OD group and cisplatin group is $140 \mu \mathrm{L} / \mathrm{mL}$ and $6 \mu \mathrm{g} / \mathrm{mL}$, and OD is $140 \mu \mathrm{L} / \mathrm{mL}$, cisplatin is $6 \mu \mathrm{g} / \mathrm{mL}$ in combined group. (A) The number of cells passed through Transwell invasion chamber in CON, OD, cisplatin, and OD + cisplatin groups. (B) Counts of cells passed through Transwell invasion chamber in four different groups. All experiments were repeated three times $(* P<0.01$ vs the control group).

Abbreviations: CON, control; OD, Oldenlandia diffusa.

A

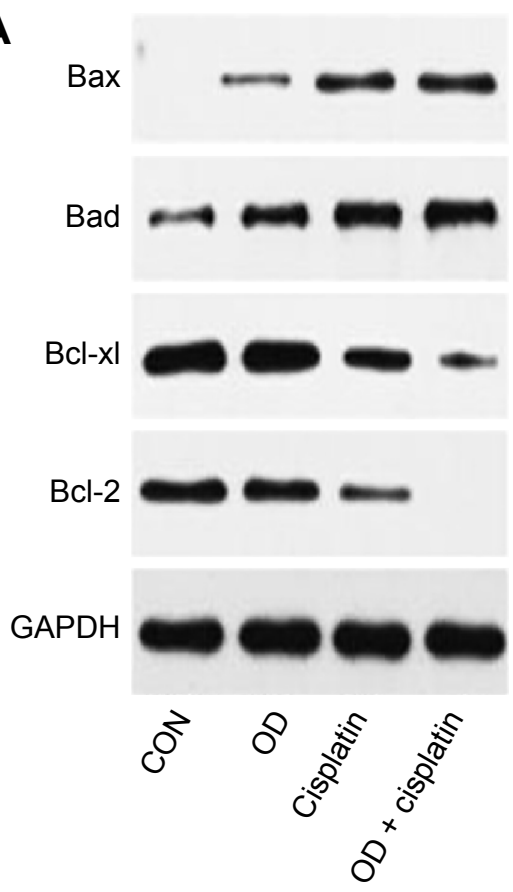

B

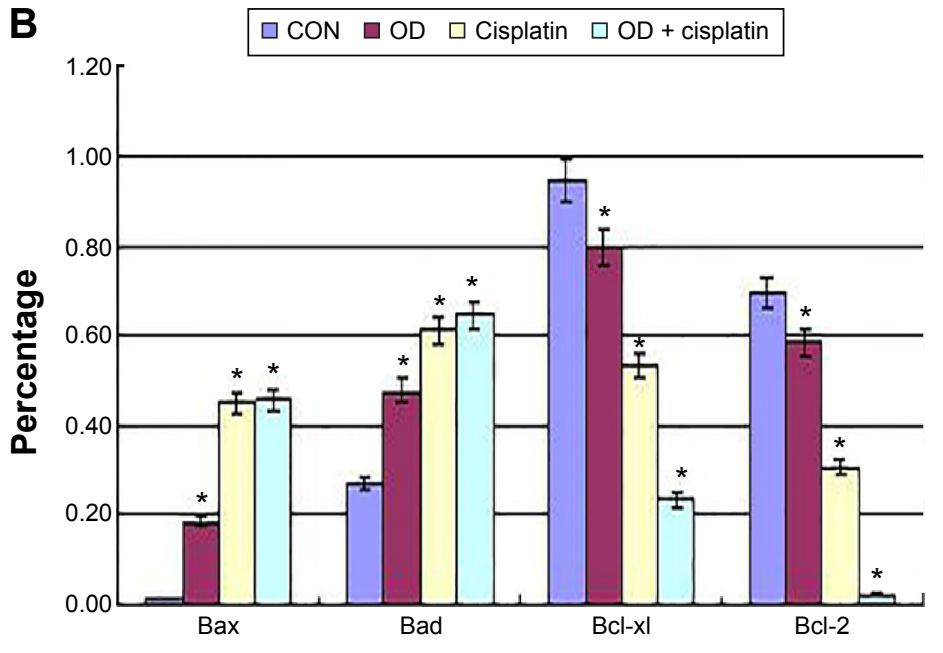

Figure 5 Western blot analysis of the anti-apoptotic and pro-apoptotic protein expression in MG-63 cells.

Notes: (A) The levels of pro-apoptotic protein (Bax and Bad) and anti-apoptotic (Bcl-xl and Bcl-2) were analyzed by Western blot analysis. There was an increase of pro-apoptotic protein (Bax and $\mathrm{Bad}$ ) and a decrease of anti-apoptotic protein (Bcl-xl and $\mathrm{Bcl}-2$ ) in the combination group (OD was $\mathrm{I} 40 \mu \mathrm{L} / \mathrm{mL}$ and cisplatin was $6 \mu \mathrm{g} / \mathrm{mL})$. (B) The mean \pm standard deviation of the results were obtained from three independent experiments ( $* P<0.0 \mathrm{I}$ vs the control group).

Abbreviations: CON, control; GAPDH, glyceraldehyde-3-phosphate dehydrogenase; OD, Oldenlandia diffusa. 

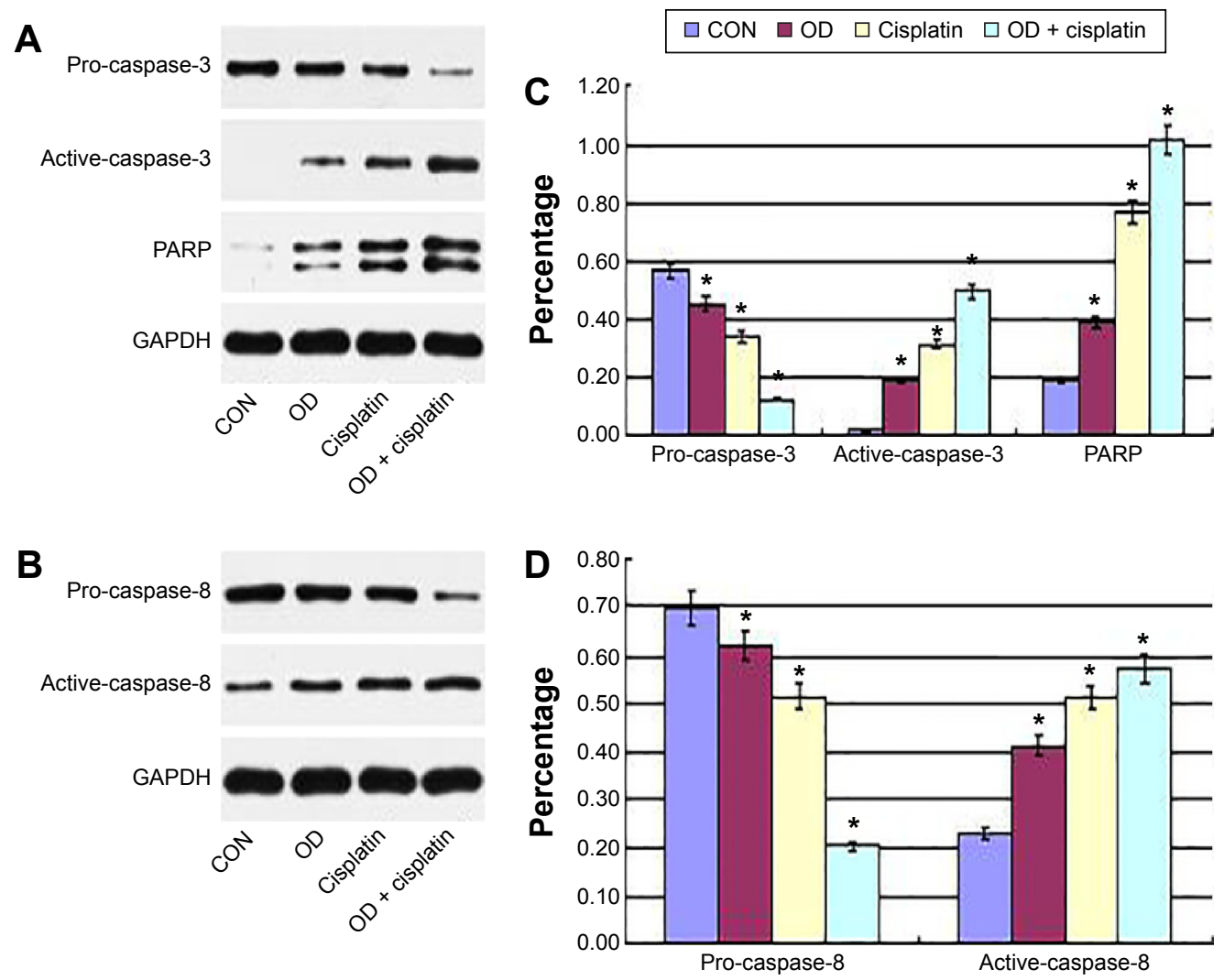

Figure 6 Western blot analysis of the expression of caspase-3 and caspase- 8 in MG-63 cells.

Notes: (A, B) The levels of caspase- 3 and caspase- 8 were analyzed by Western blot analysis. There was an increase of active caspase-3, PARP, and the active caspase-8 in the combination group (OD was $140 \mu \mathrm{L} / \mathrm{mL}$ and cisplatin was $6 \mu \mathrm{g} / \mathrm{mL}$ ). (C, D) The mean \pm standard deviation of the results was obtained from three independent experiments $(* P<0.01$ vs the control group).

Abbreviations: CON, control; GAPDH, glyceraldehyde-3-phosphate dehydrogenase; OD, Oldenlandia diffusa; PARP, poly (ADP-ribose) polymerase.

\section{Disclosure}

The authors report no conflicts of interest in this work.

\section{References}

1. Ottaviani G, Jaffe N. The epidemiology of osteosarcoma. Cancer Treat Res. 2009;152:3-13.

2. Satelli A, Mitra A, Cutrera JJ, et al. Universal marker and detection tool for human sarcoma circulating tumor cells. Cancer Res. 2014;74(6): $1645-1650$.

3. Bielack SS, Kempf-Bielack B, Delling G, et al. Prognostic factors in high-grade osteosarcoma of the extremities or trunk: an analysis of 1,702 patients treated on neoadjuvant cooperative osteosarcoma study group protocols. J Clin Oncol. 2002;20(3):776-790.

4. Foster L, Dall GF, Reid R, Wallace WH, Porter DE. Twentieth-century survival from osteosarcoma in childhood. Trends from 1933 to 2004. J Bone Joint Surg Br. 2007;89(9):1234-1238.

5. Jaffe N. Historical perspective on the introduction and use of chemotherapy for the treatment of osteosarcoma in current advances in osteosarcoma. Adv Exp Med Biol. 2014;804:1-30.

6. Bacci G, Ferrari S, Lari S, et al. Osteosarcoma of the limb. Amputation or limb salvage in patients treated by neoadjuvant chemotherapy. J Bone Joint Surg Br. 2002;84(1):88-92.

7. Dasari S, Tchounwou PB. Cisplatin in cancer therapy: molecular mechanisms of action. Eur J Pharmacol. 2014;740:364-378.

8. Zhou W, Cao A, Wang L, Wu D. Kurarinone synergizes TRAILinduced apoptosis in gastric cancer cells. Cell Biochem Biophys. Epub 2014 Dec 19
9. Gu G, Barone I, Gelsomino L, et al. Oldenlandia diffusa extracts exert antiproliferative and apoptotic effects on human breast cancer cells through ERa/Sp1-mediated p53 activation. J Cell Physiol. 2012; 227(10):3363-3372.

10. Willimott S, Barker J, Jones LA, Opara EI. Apoptotic effect of Oldenlandia diffusa on the leukaemic cell line HL60 and human lymphocytes. J Ethnopharmacol. 2007;114(3):290-299.

11. Sadava D, Ahn J, Zhan M, Pang ML, Ding J, Kane SE. Effects of four Chinese herbal extracts on drug-sensitive and multidrug-resistant smallcell lung carcinoma cells. Cancer Chemother Pharmacol. 2002;49(4): 261-266.

12. Shan BE, Zhang JY, Du XN. Immunomodulatory activity and anti-tumor activity of Oldenlandia diffusa in vitro. Zhongguo Zhong Xi Yi Jie He Za Zhi. 2001;21(5):370-374.

13. Li X, Huang T, Jiang G, Gong W, Qian H, Zou C. Synergistic apoptotic effect of crocin and cisplatin on osteosarcoma cells via caspase induced apoptosis. Toxicol Lett. 2013;221(3):197-204.

14. Salvesen GS, Walsh CM. Functions of caspase 8: the identified and the mysterious. Semin Immunol. 2014;26(3):246-252.

15. Graf RP, Keller N, Barbero S, Stupack D. Caspase-8 as a regulator of tumor cell motility. Curr Mol Med. 2014;14(2):246-254.

16. Tian HY, Li ZX, Li HY, Wang HJ, Zhu XW, Dou ZH. Effects of 14 single herbs on the induction of caspase- 3 in tumor cells: a brief review. Chin J Integr Med. 2013;19(8):636-640.

17. Snigdha S, Smith ED, Prieto GA, Cotman CW. Caspase-3 activation as a bifurcation point between plasticity and cell death. Neurosci Bull. 2012; 28(1):14-24.

18. Smith MA, Schnellmann RG. Calpains, mitochondria, and apoptosis. Cardiovasc Res. 2012;96(1):32-37. 
OncoTargets and Therapy

\section{Publish your work in this journal}

OncoTargets and Therapy is an international, peer-reviewed, open access journal focusing on the pathological basis of all cancers, potential targets for therapy and treatment protocols employed to improve the management of cancer patients. The journal also focuses on the impact of management programs and new therapeutic agents and protocols on

perspectives such as quality of life, adherence and satisfaction The manuscript management system is completely online and includes a very quick and fair peer-review system, which is all easy to use. Visit http://www.dovepress.com/testimonials.php to read real quotes from published authors.

Submit your manuscript here: http://www.dovepress.com/oncotargets-and-therapy-journal 